\title{
Gestational treatment with cocaine and fluoxetine alters oxytocin receptor number and binding affinity in lactating rat dams
}

\author{
Josephine M. Johns ${ }^{\star}$, Deborah A. Lubin, Cheryl H. Walker, Paul Joyner, Christopher \\ Middleton, Vivian Hofler, and Matthew McMurray \\ Department of Psychiatry, The University of North Carolina at Chapel Hill, 424 Taylor Hall, CB \\ \#7096, Chapel Hill, NC 27599-7096, USA
}

\begin{abstract}
Cocaine administered chronically throughout gestation has been correlated with deficits in maternal behavior, increased maternal aggressive behavior and decreased oxytocin levels in rats. In addition to its effects on oxytocin levels, cocaine is a potent serotonergic, dopaminergic and noradrenergic reuptake inhibitor. Alterations in the dopaminergic and serotonergic systems have been suggested as possibly having a role in cocaine-induced maternal aggression. This study was in part, an attempt to understand some of the mechanisms by which cocaine increases postpartum aggression, particularly as they relate to changes in the oxytocin system.

Oxytocin receptor number and binding affinity in the medial preoptic area of the hypothalamus, ventral tegmental area, hippocampus and amygdala were determined for lactating rat dams on postpartum day 6 (PPD 6) that were gestationally treated with cocaine, fluoxetine, saline or an amfonelic acid/fluoxetine drug combination. Cocaine and fluoxetine treatment both resulted in a significant up-regulation of oxytocin receptor number and lower receptor affinity in the amygdala of lactating rat dams compared to saline controls and the amfonelic acid/fluoxetine combination treatment group. Cocaine treatment also resulted in a significant down-regulation of oxytocin receptors in the medial preoptic area and both cocaine and fluoxetine treated dams had the highest affinity for oxytocin receptors in this brain region. Results of the present study support previous data indicating that alterations in oxytocinergic and perhaps serotonergic system dynamics in the amygdala may play a role in cocaine-induced postpartum aggression.
\end{abstract}

\section{Keywords \\ Cocaine; Fluoxetine; Oxytocin; Teceptor}

\section{Introduction}

A growing body of literature demonstrates that cocaine given chronically to rats throughout gestation is associated with decreased levels of the neuropeptide oxytocin (OT) (Johns et al., 1995, 1997, 1998; Elliott et al., 2001) in brain structures implicated in maternal behavior and/or maternal aggressive behavior, including the Medial pre-optic area (MPOA) of the hypothalamus (Pedersen et al., 1994), ventral tegmental area (VTA) (Numan and Smith, 1984), hippocampus (Kimble et al., 1967), and amygdala (Fleming et al., 1980; Lubin et al., 2003b). Furthermore, cocaine-induced disruptions in the onset of maternal behavior (Heyser

(C) 2004 ISDN. Published by Elsevier Ltd. All rights reserved.

"Corresponding author. Tel.: +1-919-966-5961; fax: +1-919-843-5730. jjohns@ @ed.unc.edu (J.M. Johns). 
et al., 1992; Zimmerberg and Gray, 1992; Johns et al., 1994; Kinsley et al., 1994; Vernotica et al., 1996) have been correlated with decreased OT levels in the MPOA, VTA and hippocampus (Johns et al., 1997). Cocaine-induced decreases in OT levels in the amygdala have also been associated with heightened postpartum aggression towards intruders (Johns et al., 1995, 1998).

Direct antagonism of OT activity in the VTA and MPOA has produced disruptions in maternal behavior onset in rats (Pedersen et al., 1994). More recently, blockade of OT activity in the paraventricular nucleus of the hypothalamus (Giovenardi et al., 1997, 1998) and the amygdala (Lubin et al., 2003b) has been correlated with increased maternal aggressive behavior in the lactating rat. Therefore, both cocaine-induced decreases in OT levels and direct antagonism of OT activity in relevant brain areas have been associated with altered maternal behavior and maternal aggressive behavior. In the search for mechanisms that may underlie cocaine's effects on OT and subsequent postpartum aggressive behavior, there is some evidence that cocaine-induced changes in the dynamics of both the serotonergic (5-HT) and/or dopaminergic (DA) systems could play a role (Lubin et al., 2003a). Cocaine, a central nervous system stimulant and DA, 5-HT and noradrenergic (NE) uptake inhibitor, appears to have an antagonistic relationship with OT (Kovacs et al., 1990; Sarnyai et al., 1991). Both affect common brain structures or pathways involved in maternal behavior or maternal aggression. In addition to having OT neurons, fibers and/or receptors, the paraventricular nucleus, hippocampus, amygdala, MPOA and VTA contain DA, 5-HT and NE projections, neurons or receptors (Kimble et al., 1967; Fahrbach et al., 1985; Kendrick et al., 1987; Tribollet et al., 1988; Burt, 1993; Numan, 1994; Pedersen et al., 1994). There is anatomical evidence that OT neurons are in close contact or have synaptic connections with axons of neurons of these three neurotransmitter systems (Burt et al., 1993; Horie et al., 1993) and that OT system dynamics (release, levels or receptors) can be altered by both cocaine and by manipulation of each of the aforementioned neurotransmitter systems (Rosenberg et al., 1977; Honda et al., 1985; Drago et al., 1986; Giordano et al., 1990; Kovacs et al., 1990; Cunningham et al., 1992; Kendrick et al., 1992; Sarnyai et al., 1992; Hansen, 1994; Van de Kar et al., 1995; Bagdy, 1996; Thomas and Palmiter, 1997; Ji et al., 1998; Onaka and Yagi, 1998). While there is almost no evidence for NE being involved in maternal aggression (Sorenson and Gordon, 1975), both DA and 5-HT systems are implicated as possible systems underlying aggressive behavior (Neckers et al., 1975; Ieni and Thurmond, 1985; Mos et al., 1990; Olivier and Mos, 1992; De Almeida and Lucion, 1994; Moeller et al., 1994; Olivier et al., 1995; Matto et al., 1998). In preliminary studies (Johns et al., 1995; Lomas et al., 2002), there were reported decreases or increases respectively in OT levels in the amygdala of rats treated during gestation with 5-HT or DA reuptake inhibitors. However, there is no available data evaluating the potential compensatory effects following administration of cocaine or by manipulation of either or a combination of these neurotransmitter systems during gestation on oxytocin receptors in relevant brain structures other than a very preliminary study with cocaine alone (Johns et al., 1999). Fluoxetine, a selective 5-HT uptake inhibitor, has a half-life of approximately $8-15 \mathrm{~h}$ (including its metabolites) in rats (Raap and Van de Kar, 1999) and has been successfully administered to pregnant rats (Montero et al., 1990). While FLU is selective to the 5-HT system, it is not selective to one specific receptor subtype and it is similar to cocaine in that it causes minor anorexia in rats and has been used in a previous behavioral study of maternal aggressive behavior (Lomas et al., 2002).

Amfonelic acid (AFA), a selective dopamine uptake inhibitor, at moderate doses, like cocaine is a non-amphetamine stimulant that has few effects on the noradrenergic system and has been described as very selective in vivo for protecting DA storage pool content (Fuller and Perry, 1981). AFA has been shown to cause enhancement of extrapyramidal dynorphin-like immunoreactivity similar to that shown with cocaine administration which is 
thought to result primarily from the ability of cocaine to block DA uptake (Smiley et al., 1990). AFA produces significant DA uptake blockade for about $12 \mathrm{~h}$ after injection (half life $8-12 \mathrm{~h}$ ) and produces behavioral hyperactivity and stereo-typies similar to $30 \mathrm{mg} / \mathrm{kg}$ of cocaine. While gestational treatment with AFA alone seems to decrease maternal aggression (Johns et al., 1995), it was thought that when given in combination with a sertonergic reuptake inhibitor, it may produce different results. Therefore, the present study examined the effects of gestational treatment with cocaine, fluoxetine (FLU), a combination treatment of FLU and amfonelic acid (AFA) or saline administration on OT receptor dynamics in brain areas implicated in maternal behavior and/or maternal aggression.

\section{Methods}

\subsection{Animals}

Virgin female Sprague-Dawley rats (200-225 g) were group housed in a temperature and humidity controlled room for a one-week habituation period prior to mating. Females were then singly housed with a sexually active male until conception was noted by the presence of a sperm plug and confirmation by a vaginal smear, if necessary. On the day a sperm plug was present, gestation day 0 , the female was removed from the breeding cage, assigned to one of four treatment groups, and individually housed. Singly housed pregnant females were maintained on a reversed $12 \mathrm{~h}: 12 \mathrm{~h}$ light cycle (with lights off at 09:00 h) for 8 days, then transferred to a room with a regular light cycle (lights on at 07:00 h) for the remainder of the experiment. This procedure generally results in the majority of dams delivering their litters during daylight hours (Mayer and Rosenblatt, 1998). All females except the saline-treated dams were allowed ad libitum access to food (Purina Rat Chow) and water throughout the experiment. Since both cocaine and fluoxetine have anorectic properties, the saline control group was yoked or pair-fed to the cocaine-treated dams such that they were only allowed access to as much food on any particular gestation day as the average amount of food consumed by cocaine-treated dams on that same gestation day.

\subsection{Treatment}

Ninety-six pregnant females ( 24 females/group) were assigned to one of four treatment groups, cocaine, FLU, an amfonelic acid/fluoxetine (AFA/FLU) combination group and a saline control group. All dams were injected with their respective treatments or saline throughout gestation (gestation days 1-20), subcutaneously, twice daily at approximately 9:00 a.m. and 4:00 p.m. as described below. As skin lesions are prone to develop following repeated subcutaneous administration of cocaine, injection sites for all groups were varied and drug injections were given on alternating flanks in the morning and afternoon. Any skin lesions that developed were cleaned with a Betadine wash and a treated with a topical antibacterial ointment (Polymycin-Bacitracin-Neomycin, Burroughs Wellcome, Raleigh, $\mathrm{NC}$ ) as soon as they were discovered. Cocaine-treated females were injected with $15 \mathrm{mg} / \mathrm{kg}$ of cocaine hydrochloride (dose calculated as the free base; Sigma Chemical Company, St. Louis, MO) dissolved in $0.9 \%$ normal saline, for a total daily dose of $30 \mathrm{mg} / \mathrm{kg}$ in a total volume of $2 \mathrm{ml} / \mathrm{kg}$. Saline-treated females were injected with $0.9 \%$ (normal) saline (2 ml/kg total volume).

FLU-treated dams were injected once at 9:00 am with fluoxetine hydrochloride (dose calculated as the free base; Sigma Chemical Company, St. Louis, MO) dissolved in distilled water at a concentration of $8 \mathrm{mg} / \mathrm{kg}$ and with normal saline at 4:00 p.m. each day. Since no single drug had the combined 5-HT and DA reuptake inhibition properties that we were interested in, a combined AFA/FLU treatment group was used in the present study. The AFA/Flu group received daily injections of $2.5 \mathrm{mg} / \mathrm{kg}$ of amfonelic acid (Sigma Chemical Company, St. Louis, MO) in a pH 10 solution (mixed in $0.1 \mathrm{ml} 1 \mathrm{~N} \mathrm{NaOH}$ and $0.6 \mathrm{ml}$ of 
$0.1 \mathrm{~N} \mathrm{HCl}$ dissolved in distilled water) on one rear flank and $8 \mathrm{mg} / \mathrm{kg}$ of FLU on the other flank at 9:00 a.m. and an injection of normal saline at 4:00 p.m. AFA/FLU and FLU injections were given only once daily because of their longer half-life compared to cocaine. Cocaine, FLU and AFA were stored in amber bottles and the cocaine and saline solution was maintained in a standard refrigerator when not in use. New solutions of cocaine and FLU were prepared every three days while AFA was prepared daily.

Immediately following delivery of their last pup, maternal weight, number and sex of the pups, as well as litter weight was recorded for each dam. Surrogate litters of eight males that were delivered within $12 \mathrm{~h}$ of treatment litter birth were then placed with the rat dams and remained with her until postpartum day 6 (PPD 6), when dams were killed. The culled litter size and sex was selected based on previous investigations documenting that this size litter was more than adequate to maintain maternal behavior (Zimmerberg and Gray, 1992; Vernotica et al., 1996; Vernotica and Morrell, 1998) and because all male litters have been previously used for aggression testing (Johns et al., 1994).

\subsection{Brain dissections}

Dams were decapitated between 10:00 and 12:00 a.m. and the whole hippocampus, amygdala, VTA, and MPOA brain regions were dissected on ice. Brains were coronally sectioned from the ventral side rostral to the optic chiasm [approximately A7100 according to Konig and Klippel (1963) and just caudal to the optic chiasm (approximately A5800) to define the preoptic-anterior hypothalamic area]. The MPOA was dissected by making a horizontal cut ventral to the anterior commisure and vertical cuts inferior to the lines of lateral ventricles. The brains were sectioned once again just caudal to the tuber cinereum (approximately A3800) to define the medial basal hypothalamus. The amygdala was removed from these two sections. The whole hippocampus was then removed from the caudal remainder of the brain, and the VTA dissected from this portion by making dorsoventral cuts medial to the optic tracts with a dorsal cut at the ventral extent of the central gray. Following dissection, brain sections were weighed, rapidly frozen, and stored at -70 ${ }^{\circ} \mathrm{C}$ for subsequent binding assay.

\subsection{Plasma membrane preparation}

Brain region samples from eight animals per group were combined to have sufficient tissue to assay an eleven-point saturation curve. Each curve was repeated three times. The pooled brain samples were homogenized in 19 vol. of cold $0.32 \mathrm{M}$ sucrose containing $1 \mathrm{mM}$ EDTA in $40 \mathrm{mM}$ Tris- $\mathrm{HCl}, \mathrm{pH}$ 7.4. The homogenate was centrifuged at $3000 \times g$ for $10 \mathrm{~min}$., and the supernatent was spun at $48,000 \times g$ for $15 \mathrm{~min}$. The pellet was resuspended in $40 \mathrm{mM}$ Tris- $\mathrm{HCl}, \mathrm{pH} 7.4$, and recentrifuged $(48,000 \times g$ for $15 \mathrm{~min})$. The final plasma membrane pellet was resuspended in assay buffer ( $40 \mathrm{mM}$ Tris- $\mathrm{HCl}, \mathrm{pH} 7.4,1 \mathrm{mg} / \mathrm{ml} \mathrm{BSA}$ and $10 \mathrm{mM}$ $\mathrm{MnCl}_{2}$ ) at a protein concentration of approximately $\left.200 \mu \mathrm{g} / 100 \mu \mathrm{l}\right)$.

\section{5. ${ }^{125}$ I-OTA saturation binding}

Oxytocin receptor binding was measured in rat brain plasma membranes using ${ }^{125}$ I-OTA, $\left[\mathrm{d}\left(\mathrm{CH}_{2}\right)_{5}, \mathrm{O}-\mathrm{Me}-\mathrm{Tyr}^{2}, \mathrm{Thr}^{4}, \mathrm{Tyr}^{9}, \mathrm{Orn}^{8}\right]$-vasotocin (OTA) (New England Nuclear, Boston MA). Saturation binding incubations were initiated by adding the membrane preparation to assay buffer containing eleven concentrations of ${ }^{125}$ I-OTA $(0.05-3 \mathrm{nM})$ in a final volume of $200 \mu \mathrm{l}$ in a 96-well Type B Glass Fiber filter plate for the Millipore MultiScreen system. After a $2 \mathrm{~h}$ incubation at $22{ }^{\circ} \mathrm{C}$, the samples were vacuum filtered and rapidly washed with 2 vol. of $200 \mu \mathrm{l}$ of cold assay buffer to separate bound and free radioligand. Non-specific binding was determined with a 1000-fold excess of unlabelled oxytocin. Filters were dried and counted in a LKB CliniGamma counter. Saturation binding data was analyzed using the iterative curve-fitting program PRISM by GraphPAD (San Diego, CA) to determine the 
binding parameters, receptor number $\left(B_{\max }\right)$ and receptor affinity $\left(K_{\mathrm{D}}\right)$, in each brain region for each treatment group.

\subsection{Data analysis}

Receptor number and affinity, as determined by ${ }^{125}$ I-OTA binding, were analyzed using an analyses of variance to compare values for treatment groups followed by Tukey's HSD for post-hoc comparisons of significant main effects. Gestational variables were analyzed using a one-way analyses followed by Tukey's HSD for post-hoc comparisons of significant main effects. Mean and standard error of the mean values and probability levels are presented in tables or text when appropriate. A probability level of $P \leq 0.05$ was established as the significance level for rejection of the null hypothesis. The higher the mean value for $B_{\max }$, the greater the number of bound receptors whereas a higher $K_{\mathrm{D}}$ indicates a lower receptor affinity.

\section{Results}

\subsection{Gestational variables}

There were no significant treatment related differences in the number of live or dead pups, number of male versus female pups, or litter weight among groups (data not shown). FLU treated dams gained more weight (157.67 \pm 4.37$)$ over gestation than did the AFA/FLU dams $(134.45 \pm 4.47 ; P<0.01)$. FLU-treated dams also had a trend for a slightly longer gestation length than other dams (data not shown).

\subsection{OT receptor dynamics}

3.2.1. Receptor number $\left(B_{\max }\right)$ - The results of the saturation binding data demonstrate significant changes in receptor number $\left(B_{\max }\right)$ in the amygdala and MPOA. As summarized in Table 1, there was an up-regulation of ${ }^{125}$ I-OTA receptor number in the amygdala of the cocaine and FLU treatment groups compared to saline $(P<0.01)$. In the combined AFA/ FLU treatment subjects, the addition of AFA counteracted this up-regulation such that the $B_{\max }$ in the AFA/Flu group was significantly lower than both the FLU and cocaine-treated groups (Fig. 1).

These trends were reversed in the MPOA. OT receptors (OTR) in cocaine-treated animals were significantly down-regulated $(P<0.02)$ compared to saline controls (Fig. 2 , cocaine and saline groups only represented). The FLU treatment group also showed less binding than did saline controls (ns), but the AFA/Flu treatment group did not exhibit this decrease. The hippocampal data was similar in pattern to the MPOA though differences were not significantly different. The VTA had lower binding overall and no significant differences between groups were evident.

3.2.2. Receptor affinity $\left(K_{\mathbf{D}}\right)$ - As shown in Table 2, cocaine and FLU treated subjects had lower OT receptor affinity in the amygdala. The FLU group exhibited significantly lower affinity than both saline and AFA/FLU treatment groups $(P<0.01)$, while affinity in the cocaine-treated group was significantly lower only than the AFA/Flu treatment $(P<$ 0.01 ). The cocaine treated rats in particular and FLU subjects less so, had strong trends indicative of higher receptor affinity compared to control and AFA/FLU treated groups in the MPOA and hippocampal regions.

\section{Discussion}

This is the first report of which we are aware that indicates there are both FLU and cocaineinduced alterations in the number and affinity of OTRs for the highly selective, high affinity 
ligand ${ }^{125}$ I-OTA (Elands et al., 1987) in the amygdala and MPOA (cocaine only) in lactating rats on PPD 6. OTR up-regulation in the amygdala was predicted for the cocaine-treated and FLU-treated dams given previously described oxytocin level reductions found on PPD 6 following this treatment regimen (Johns et al., 1998; Lomas et al., 2002). When there is rapid binding with slow dissociation then a ligand is thought to have greater affinity for a receptor. One might expect a greater biological effect when ligands show a higher affinity for a receptor since they would bind more receptors within a particular time period as opposed to when receptors show lower affinity and thus less binding for a particular ligand. The lower OTR affinity found following cocaine and fluoxetine treatments may indicate that even though there is an up-regulation in receptor number, the lower affinity for these receptors might reduce the overall biological effect that up-regulation could have. It is unclear exactly what the treatments do to change the binding affinity and this will be explored in future studies. The addition of AFA to FLU in the AFA/FLU treatment appears to offset the effects of FLU alone on OTR dynamics. While this magnitude of effect following the combination treatment was not predicted, it supports preliminary data from our lab indicating that treatment with a DA reuptake inhibitor increases OT levels in the amygdala during the postpartum period (Johns et al., 1995).

Generally increased 5-HT activity is related to decreased aggressive behavior in rodents and other animals (De Almeida and Lucion, 1994; Olivier et al., 1985; Olivier and Mos, 1992, 1995). It is unclear at this point what the functional effects of this gestational cocaine regimen are on the 5-HT system. In a recent report (Lubin et al., 2003a) there was a slight increase in levels of 5-HT in the amygdala on PPD 6 following a dose and regimen similar to the one used in the present study. This data might indicate that the effects we have seen on aggression following chronic cocaine treatment are, as we suspect primarily mediated by OT, but that cocaine-induced alterations of the 5-HT system might have secondary effects on the OT system.

One of the more interesting results was how closely FLU treatment parallels the effects of cocaine on OTR number and affinity in the amygdala compared to AFA/FLU treatment. Had we used an AFA treatment alone we would have predicted the effects we saw in the AFA/FLU treatment group given that in a previous study, AFA treatment with the dose used in the present study resulted in higher levels of OT in the amygdala than controls (PPD 8) and lower aggression on PPD 6 (Johns et al., 1995). Pedersen et al. (1994) found no significant differences in OTR $B_{\max }$ or affinity in the amygdala among untreated dams sacrificed during mid-parturition versus those killed between postpartum days 5 and 7 . Therefore, the changes in amygdaloidal OTRs in cocaine and FLU-treated groups on PPD 6 in the current investigation appear to be treatment dependent.

It is unclear how or if DA or 5-HT regulates release of OT in the amygdala, although the paraventricular nucleus, which is the main site for OT synthesis and projection, receives inhibitory 5-HT and DA inputs to the magnocellular OT neurons and these inhibitory systems are activated under stressful conditions such as might occur when faced with an intruder (Honda et al., 1985; Burt, 1993). How much effect these inhibitory systems may ultimately have is questionable given that chronic cocaine administration has been shown to decrease 5-HT's regulation of neuroendocrine responses, including the release of OT (Levy et al., 1992). A number of 5-HT agonists can stimulate peripheral OT release (Bagdy, 1996; Saydoff et al., 1991; Uvnas-Moberg et al., 1996), and D1 receptor agonists stimulate while D2 receptor agonists can inhibit OT release (Crowley et al., 1991). It has also been demonstrated that administration of OT alters monoamine concentrations in various brain regions (Pfister and Muir, 1989). Future studies manipulating these neurotransmitter systems may prove valuable in an attempt to discern how they are interacting with OT following cocaine administration. 
In the present study, there was actually a significant down-regulation of OT receptors in the MPOA (cocaine only) and non-significant trends toward down-regulation of OTRs in the hippocampus and VTA of cocaine and FLU treated dams. Since cocaine-induced alterations in OT levels were not previously found in the VTA or MPOA on PPD 6 (Johns et al., 1997, 1998), clearly the down-regulation in the MPOA does not follow level changes and in fact data from both the present and previous studies indicate that OTRs may be resistant to cocaine-induced alterations of levels in some brain regions. The putative lack of consistency of OTR regulation with level alterations in various brain regions on PPD 6 may simply corroborate Insel's (1992) findings that OT poorly regulates OTRs though it is quite likely that OT activity modulates OTRs in certain circumstances. Engstrøm et al. (1999) demonstrated that an OT antagonist significantly decreased $B_{\max }$ without altering the affinity of OTRs in rat myometrium [the same type of OTR as in brain (Breton and Zingg, 1997)] during labor, when there is normally a significant increase in OTR number (Engstrøm et al., 1999). In addition, OT increased the affinity of OTRs in the MPOA and medial basal hypothalamus by converting low affinity sites to high affinity sites, in vitro, within 30 min of a $2 \mathrm{nM}$ OT exposure (Walker, personal communication, December 2004).

The current investigation did not examine whether there were cocaine-or FLU induced alterations in transcription or translation of OTRs, or the integrity of the post-synaptic signaling cascade (including altered G-protein coupling, the phosphoinositol calcium signal transduction pathway, or subsequent cytosolic calcium concentrations (Barberis et al., 1998). Ivell and Walther (1999) note that there is a role for indirect regulation of OT and OTRs either via activation of various intermediaries that ultimately activate the genes, or through direct activation of steroid receptors on the relevant cell membranes. It is quite possible given this data that 5-HT receptor activation may be directly regulating OTR activity independently of OT or other mechanisms and there are 5-HT receptors as well as OTR located in the MPOA and amygdala. The effects of cocaine and FLU treatment on OT mRNA are now being investigated in our laboratory.

This study was one in a series of studies recently undertaken to examine possible mechanisms underlying cocaine-induced alterations in oxytocin system dynamics and to further examine the hypothesis that cocaine induced alterations in postpartum aggression in rats are related to changes in the OT system in the amygdala. If indeed, cocaine does alter postpartum aggression primarily through its effects on the OT system it may do so either directly or perhaps indirectly acting through one or a combination of the neurotransmitter systems it affects. In conclusion, OTR number and binding affinity in the amygdala were altered by both cocaine and FLU in the expected direction. The combination treatment of AFA/FLU resulted in control levels of OTR binding and affinity suggesting perhaps a lesser role for the DA system in cocaine-induced levels of post-partum aggression though its effects are interesting and require further characterization. This study therefore provides additional, albeit indirect, evidence that cocaine-induced decreases in OT levels and lower receptor affinity in the amygdala may play a role in increased postpartum aggressive behavior in rat dams and that 5-HT reuptake inhibition (at the dose used in this study) produces effects similar to cocaine on OT receptor system dynamics in the amygdala on PPD 6 and may play some role in the effect of gestational cocaine treatment on postpartum aggression in the rat.

\section{Acknowledgments}

This project was supported by NIH grant DA13283-01A1 (J.M.J.). We would like to thank our consultant on this project Dr. Brian McMillen. 


\section{Abbreviations}

\begin{tabular}{|c|c|}
\hline OT & oxytocin \\
\hline NE & norepinephrine \\
\hline 5-HT & serotonin \\
\hline DA & dopamine \\
\hline MPOA & medial preoptic area \\
\hline VTA & ventral tegmental area \\
\hline FLU & fluoxetine \\
\hline AFA & amfonelic acid \\
\hline OTR & oxytocin receptors \\
\hline OTA & ${ }^{125}$ I-OTA, $\left[\mathrm{d}\left(\mathrm{CH}_{2}\right)_{5}, \mathrm{O}-\mathrm{Me}-\mathrm{Tyr}^{2}, \mathrm{Thr}^{4}, \mathrm{Tyr}^{9}, \mathrm{Orn}^{8}\right]$-vasotocin \\
\hline$B_{\max }$ & receptor number \\
\hline$K_{\mathrm{D}}$ & receptor affinity \\
\hline PPD & postpartum day \\
\hline fmol & fentamoles \\
\hline $\mathbf{p M}$ & picomoles \\
\hline
\end{tabular}

\section{References}

Bagdy G. Role of the hypothalamic paraventricular nucleus in 5- $\mathrm{HT}_{1 \mathrm{~A}}, 5-\mathrm{HT}_{2} \mathrm{~A}$, and 5- $\mathrm{HT}_{2 \mathrm{C}}$ receptor-mediated oxytocin, prolactin, and ACTH/corticosterone responses. Behav Brain Res. 1996; 73:277-280. [PubMed: 8788518]

Barberis C, Mouillac B, Durroux T. Structural bases of vasopressin/oxytocin receptor function. J Endocrinol. 1998; 156:223-229. [PubMed: 9518866]

Breton C, Zingg HH. Expression and region-specific regulation of the oxytocin receptor gene in rat brain. Endocrinology. 1997; 138:1857-1862. [PubMed: 9112379]

Burt, A. Textbook of Neuroanatomy. Saunders; Philadelphia: 1993.

Burt S, Shioda S, Nakai Y. Catecholinergic innervation of oxytocin neurons in the paraventricular nucleus of the rat hypothalamus as revealed by double-labeling imunnoelectron microscopy. Acta Anat. 1993; 147:184-192. [PubMed: 8213044]

Crowley WR, Parker SL, Armstrong WE, Wang W, Grosvenor CE. Excitatory and inhibitory dopaminergic regulation of oxytocin secretion in the lactating rat: evidence for respective mediation by D-1 and D-2 dopamine receptor subtypes. Neuroendocrinology. 1991; 53:493-502. [PubMed: 1831247]

Cunningham KA, Paris JM, Goeders NE. Chronic cocaine enhances serotonin autoregulation and serotonin uptake binding. Synapse. 1992; 11:112-123. [PubMed: 1385662]

De Almeida RMM, Lucion AB. Effects of intracerebro-ventricular administration of 5-HT receptor agonists on the maternal aggression of rats. Eur J Pharmacol. 1994; 264:445-448. [PubMed: 7698186]

Drago F, Pedersen CA, Caldwell JD, Prange AJ Jr. Oxytocin potently enhances novelty-induced rooming behavior in the rat. Brain Res. 1986; 368:287-295. [PubMed: 3697728]

Elands J, Barberis C, Jard S, Tribollet E, Dreifuss JJ, Bankowski K, Manning M, Sawyer WH. ${ }^{125} \mathrm{I}-$ labeled d $\left(\mathrm{CH}_{2}\right)_{5}\left[\mathrm{Tyr}(\mathrm{Me})^{2}, \mathrm{Thr}^{4}\right.$, Tyr- $\left.\mathrm{NH}_{2}{ }^{9}\right] \mathrm{OVT}$ : a selective oxytocin receptor ligand. Eur J Pharmacol. 1987; 147:197-207. [PubMed: 2835249]

Elliott JC, Lubin DA, Walker CH, Johns JM. Acute cocaine alters oxytocin levels in the medial preoptic area and amygdala in lactating rat dams: implication for cocaine-induced changes in 
maternal behavior and maternal aggression. Neuropeptides. 2001; 35:127-134. [PubMed: $11384208]$

Engstrøm T, Bratholm P, Vilhardt H, Christensen NJ. Effect of oxytocin receptor and $\beta 2$-adrenoceptor blockade on myometrial oxytocin receptors in parturient rats. Biol Reprod. 1999; 60:322-329. [PubMed: 9915997]

Fahrbach, SE.; Morrell, JI.; Pfaff, DW. Role of oxytocin in onset of estrogen-facilitated maternal behavior. In: Amico, J.; Robinson, AG., editors. Oxytocin: Clinical and Laboratory Studies. Elsevier; Amsterdam: 1985. p. 372-388.

Fleming AS, Vaccarino F, Luebke C. Amygdaloid inhibition of maternal behavior in the nulliparous female rat. Physiol Behav. 1980; 25:731-743. [PubMed: 7443835]

Fuller RW, Perry KW. Amfonelic acid antagonism of dopamine and norepinephrine depletion by amethyl- $m$-tyrosine in rat brain. Biochem Pharmacol. 1981; 30:2025-2026. [PubMed: 7271892]

Giordano AL, Johnson AE, Rosenblatt JS. Haloderipol-induced disruption of retrieval behavior and reversal with apomorphine in lactating rats. Physiol Behav. 1990; 48:211-214. [PubMed: 2236274]

Giovenardi M, Padoin MJ, Cadore LP, Lucion AB. Hypothalamic paraventricular nucleus, oxytocin, and maternal aggression in rats. Ann NY Acad Sci. 1997; 807:606-609. [PubMed: 9071411]

Giovenardi M, Padoin MJ, Cadore LP, Lucion AB. Hypothalamic paraventricular nucleus modulates maternal aggression in rats: effects of ibotenic acid lesion and oxytocin antisense. Physiol Behav. 1998; 63:351-359. [PubMed: 9469726]

Hansen S. Maternal behavior of female rats with 6-OHDA lesions in the ventral striatum: characterization of the pup retrieval deficit. Physiol Behav. 1994; 55:615-620. [PubMed: 8190785]

Heyser CJ, Molina VA, Spear LP. A fostering study of the effects of prenatal cocaine exposure. I. Maternal behaviors. Neurotoxicol Teratol. 1992; 14:415-421. [PubMed: 1488036]

Honda K, Negoro H, Fukuoka T, Higuchi T, Uchide K. Effect of microelectrophoretically applied acetylcholine, noradrenaline, dopamine and serotonin on the discharge of paraventricular oxytocinergic neurones in the rat. Endocrinology (Japan). 1985; 32:127-133.

Horie S, Shioda S, Nakai Y. Catecholinergic innervation of oxytocin neurons in the paraventricular nucleus of the rat hypothalamus as revealed by double-labeling imunnoelectron microscopy. Acta Anat. 1993; 147:184-192. [PubMed: 8213044]

Ieni JR, Thurmond JB. Maternal aggression in mice: effects of treatments with PCPA, 5-HTP and 5HT receptor antagonists. Eur J Pharmacol. 1985; 111:211-220. [PubMed: 3160594]

Insel TR. Oxytocin-A neuropeptide for affiliation: evidence from behavioral, receptor autoradiographic, and comparative studies. Psychoneuroendocrinology. 1992; 17:3-35. [PubMed: 1319071]

Ivell R, Walther N. The role of sex steroids in the oxytocin hormone system. Mol Cell Endocrinol. 1999; 151:95-101. [PubMed: 10411324]

Ji Y, Mei J, Lu S. Opposing effects of intracerebroventricularly injected norepinephrine on oxytocin and vasopressin neurons in the paraventricular nucleus of the rat. Neurosci Lett. 1998; 244:13-16. [PubMed: 9578133]

Johns JM, Faggin BM, Noonan LR, Li L, Zimmerman LI, Pedersen CA. Chronic cocaine treatment decreases oxytocin levels in the amygdala and increases maternal aggression in Sprague-Dawley rats. Soc Neurosci. 1995; 21:766. (abstract).

Johns JM, Lubin DA, Walker CH, Hill J, Meter KE. Gestational cocaine treatment differentially alters oxytocin receptors in the amygdala and hippocampus of postpartum rats. Int Behav Neurosci Soc. 1999 (abstract).

Johns JM, Lubin DA, Walker CH, Meter KE, Mason GA. Chronic gestational cocaine treatment decreases oxytocin levels in the medial preoptic area, ventral tegmental area and hippocampus in Sprague-Dawley rats. Neuropeptides. 1997; 31:439-443. [PubMed: 9413020]

Johns JM, Noonan LR, Zimmerman LI, Li L, Pedersen CA. Effects of chronic and acute cocaine treatment on the onset of maternal behavior and aggression in Sprague-Dawley rats. Behav Neurosci. 1994; 108:107-112. [PubMed: 8192835] 
Johns, JM.; Noonan, LR.; Zimmerman, LI.; McMillen, BA.; Means, LW.; Walker, CH.; Lubin, DA.; Meter, KE.; Nelson, CJ.; Pedersen, CA.; Mason, GA.; Lauder, JM. Chronic cocaine treatment alters social/aggressive behavior in Sprague-Dawley rat dams and their prenatally exposed offspring. Cocaine: Effects on the Developing Brain. In: Harvey, JA.; Kosofsky, BE., editors. Ann NY Acad Sci. 1998. p. 846

Kendrick KM, Keverne EB, Baldwin BA. Intracerebroventricular oxytocin stimulates maternal behavior in the sheep. Neuroendocrinology. 1987; 46:56-61. [PubMed: 3614555]

Kendrick KM, Keverne EB, Hinton MR, Goode JA. Oxytocin, amino acid and monoamine release in the region of the medial preoptic area and bed nucleus of the stria terminalis of the sheep during parturition and suckling. Brain Res. 1992; 569:199-209. [PubMed: 1540826]

Kimble DP, Rogers L, Hendrickson CW. Hippocampal lesions disrupt maternal, not sexual behavior in the albino rat. J Comp Physiol Psychol. 1967; 63:401-407. [PubMed: 6064383]

Kinsley CH, Turco D, Bauer A, Beverly M, Wellman J, Graham AL. Cocaine alters the onset and maintenance of maternal behavior in lactating rats. Pharmacol Biochem Behav. 1994; 47:857-864. [PubMed: 8029256]

Konig, JFR.; Klippel, RA. The Rat Brain: A Stereotaxic Atlas of the Forebrain and Lower Parts of the Brain Stem. Krieger; New York: 1963.

Kovacs GL, Sarnyai Z, Babarczi E, Szabo G, Telegdy G. The role of oxytocin-dopamine interactions in cocaine-induced locomotor hyperactivity. Neuropharmacology. 1990; 29:365-368. [PubMed: 2160623]

Levy AD, Li Q, Alvarez Sanz MC, Rittenhouse PA, Kerr JE, Van de Kar LD. Neuroendocrine responses to cocaine do not exhibit sensitization following repeated cocaine exposure. Life Sci. 1992; 51:887-897. [PubMed: 1325586]

Lomas LM, Joyner PW, Ardalan C, Lubin DA, Middleton CL, Holfler V, Knupp K, Goldhammer R, Johns JM. A comparison of the effects of a serotonergic and dopaminergic-serotonergic combination reuptake inhibitor on maternal aggressive. Soc Neurosci. 2002:90.5. (abstract).

Lubin DA, Cannon JB, Black MC, Brown LE, Johns JM. Effects of chronic cocaine on monoamine levels in discrete brain structures of lactating rat dams. Pharmacol Biochem Behav. 2003a; 74(2): 449-454. [PubMed: 12479966]

Lubin DA, Elliott JC, Black MC, Johns JM. An oxytocin antagonist infused into the central nucleus of the amygdala increases maternal aggressive behavior. Behav Neurosci. 2003b; 117(2):195-201. [PubMed: 12708515]

Matto V, Allikmets L, Skrebuhhova T. Apomorphine-induced aggressiveness and $\left[{ }^{3} \mathrm{H}\right]$ citalopram binding after antidepressant treatment in rats. Pharmacol Biochem Behav. 1998; 59(3):747-752. [PubMed: 9512081]

Mayer AD, Rosenblatt JS. A method for regulating the duration of pregnancy and the time of parturition in Sprague-Dawley rats. Dev Psychobiol. 1998; 32:131-136. [PubMed: 9526688]

Moeller FG, Steinberg JL, Petty F, Fulton M, Cherek DR, Kramer G, Garver DL. Serotonin and impulsive/aggressive behavior in cocaine dependent subjects. Prog Neuropsychoph. 1994; 18:1027-1035.

Montero D, de Ceballos ML, Del Rio J. Down-regulation of ${ }^{3} \mathrm{H}$-imipramine binding sites in cerebral cortex after prenatal exposure to antidepressants. Life Sci. 1990; 46:1619-1626. [PubMed: 2161976]

Mos J, Olivier B, van Oorschot R. Behavioural and neuropharmacological aspects of maternal aggression in rodents. Agg Behav. 1990; 16:145-163.

Neckers LM, Zarrow MX, Myers MM, Denenberg VH. Influence of olfactory bulbectomy and the serotonergic system upon intermale aggression and maternal behavior in the mouse. Pharmacol Biochem Behav. 1975; 3:545-550. [PubMed: 242012]

Numan, M. Maternal behavior. In: Knobil, E.; Neill, JD., editors. The Physiology of Reproduction. Raven Press; New York: 1994. p. 221-301.

Numan M, Smith HG. Maternal behavior in rats: evidence for the involvement of preoptic projections to the ventral tegmental area. Behav Neurosci. 1984; 98:712-727. [PubMed: 6087844]

Olivier B, Mos J. Rodent models of aggressive behavior and serotonergic drugs. Prog Neuropsychoph. 1992; 16:847-870. 
Olivier B, Mos J, van Oorschot R, Hen R. Serotonin receptors and animal models of aggressive behavior. Pharmacopsychiatry. 1995; 28 (Suppl 2):80-89. [PubMed: 8614705]

Onaka T, Yagi K. Role of noradrenergic projections to the bed nucleus of the stria terminalis in neuroendocrine and behavioral responses to fear-related stimuli in rats. Brain Res. 1998; 788:287293. [PubMed: 9555060]

Pedersen CA, Caldwell JD, Walker CH, Ayers G, Mason GA. Oxytocin activates the postpartum onset of rat maternal behavior in the ventral tegmental and medial preoptic areas. Behav Neurosci. 1994; 108:1163-1171. [PubMed: 7893408]

Pfister HP, Muir JL. Influence of exogenously administered oxytocin on central noradrenaline, dopamine and serotonin levels following psychological stress in nulliparous female rats (Rattus norvegicus). Int J Neurosci. 1989; 45:221-229. [PubMed: 2744963]

Raap DK, Van de Kar LD. Selective serotonergic uptake inhibitors and neuroendocrine function. Life Sci. 1999; 65:1217-1235. [PubMed: 10503938]

Rosenberg P, Halaris A, Moltz H. Effects of central norepinephrine depletion on the initiation and maintenance of maternal behavior in the rat. Pharmacol Biochem Behav. 1977; 6:21-24. [PubMed: 850689]

Sarnyai Z, Babarczy E, Krivan M, Szabo G, Kovacs GL, Barth T, Telegdy G. Selective attenuation of cocaine-induced stereotyped behavior by oxytocin: putative role of basal forebrain target sites. Neuropeptides. 1991; 19:51-56. [PubMed: 1891073]

Sarnyai Z, Biro E, Babarczy E, Vecsernyes M, Laczi G, Szabo G, Krivan M, Kovacs GL, Telegdy G. Oxytocin modulates behavioral adaptation to repeated treatment with cocaine in rats. Neuropharmacology. 1992; 31:593-598. [PubMed: 1407399]

Saydoff JA, Rittenhouse PA, Van de Kar LD, Brownfield MS. Enhanced serotonergic transmission stimulates oxytocin secretion in conscious male rats. J Pharmacol Exp Ther. 1991; 257:95-99. [PubMed: 1850481]

Smiley PL, Johnson M, Bush L, Gibb JW, Hanson GR. Effects of cocaine on extrapyramidal and limbic dynorphin systems. J Pharmacol Exp Ther. 1990; 253(3):938-943. [PubMed: 1972755]

Sorenson CA, Gordon M. Effects of 6-hydroxydopamine on shock-elicited aggression, emotionality and maternal behavior in female rats. Pharmacol Biochem Behav. 1975; 3:331-335. [PubMed: 1098058]

Thomas SA, Palmiter RD. Impaired maternal behavior in mice lacking norepinephrine and epinephrine. Cell. 1997; 91:583-592. [PubMed: 9393852]

Tribollet E, Barberis C, Jard S, Dubois-Dauphin M, Dreifuss JJ. Localization and pharmacological characterization of high affinity binding sites for vasopressin and oxytocin in the rat brain by light microscopic autoradiography. Brain Res. 1988; 442:105-118. [PubMed: 2834008]

Uvnas-Moberg K, Hillegaart V, Alster P, Ahlenius S. Effects of 5-HT agonists, selective for different subtypes, on oxytocin, CCK, gastrin and somatostatin plasma levels in the rat. Neuropharmacology. 1996; 35:1635-1640. [PubMed: 9025112]

Van de Kar LD, Rittenhouse PA, Li Q, Levy AD, Brownfield MS. Hypothalamic paraventricular, but not supraoptic neurons, mediate the serotonergic stimulation of oxytocin secretion. Brain Res Bull. 1995; 36(1):45-50. [PubMed: 7882048]

Vernotica EM, Lisciotto CA, Rosenblatt JS, Morrell JI. Cocaine transiently impairs maternal behavior in the rat. Behav Neurosci. 1996; 110:315-323. [PubMed: 8731058]

Vernotica EM, Morrell JI. Plasma cocaine levels and locomotor activity after systemic injection in virgin and in lactating maternal female rats. Physiol Behav. 1998; 64:399-407. [PubMed: 9748111]

Zimmerberg B, Gray MS. The effects of cocaine on maternal behaviors in the rat. Physiol Behav. 1992; 52:379-384. [PubMed: 1523266] 


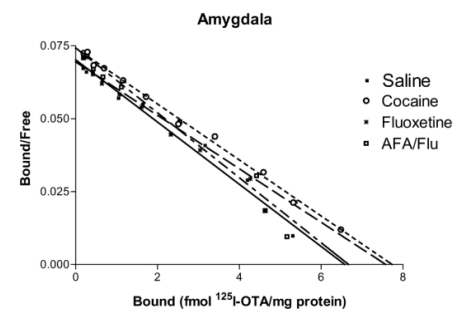

Fig. 1.

125 I-OTA saturation binding curves in the amygdala represented by scatchard plots for cocaine, fluoxetine (FLU), amfonelic acid/fluoxetine (AFA/FLU) and saline treated groups on postpartum day 6 . Lines are composites of three determinations for each treatment. $B_{\max }$ and $K_{\mathrm{D}}$ data are given in Tables 1 and 2 . The cocaine and fluoxetine groups displayed an upregulation of receptor binding $\left(B_{\max }\right)$ compared to the saline treated group $(P<0.01)$ and lower binding affinity $\left(K_{\mathrm{D}}\right)$ compared to the AFA/FLU combination $(P>0.01$, cocaine and fluoxetine) and saline treatment groups $(P<0.01$, fluoxetine only). 


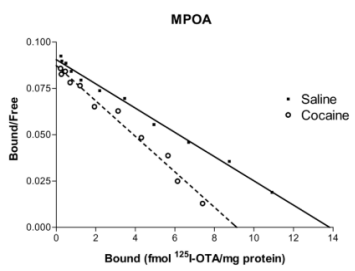

Fig. 2.

${ }^{125}$ I-OTA saturation binding curves in the MPOA represented by scatchard plots. Lines are composites of three determinations for cocaine and saline treated groups (fluoxetine and amfonelic acid/fluoxetine not represented) on postpartum day 6. Cocaine treatment resulted in a significant down-regulation of receptor binding $(P<0.02)$ compared to saline-treated controls. $B_{\max }$ and $K_{\mathrm{D}}$ data are given in Tables 1 and 2. 


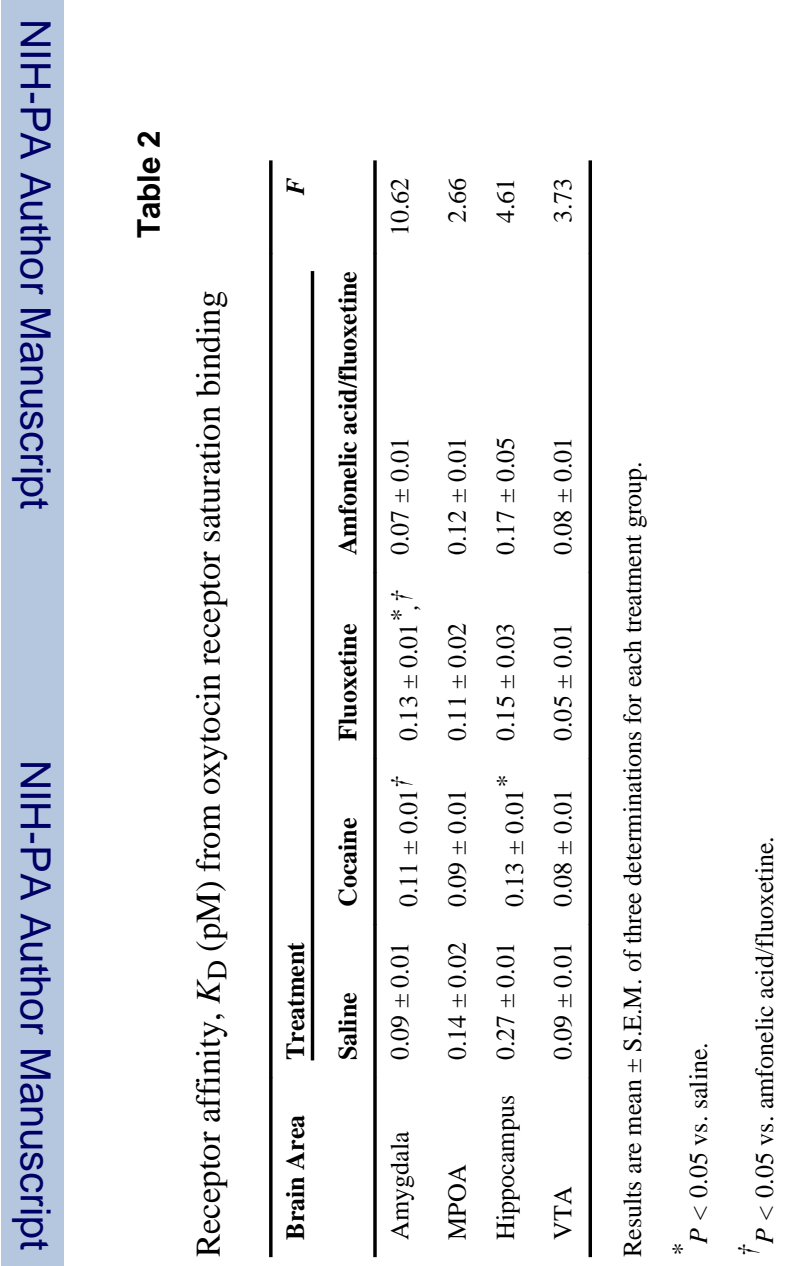

